youngsters was performed. In this study it was assessed whether the education level of youngsters was associated with various sexual health topics.

Methods A total of 3772 youngsters between 12-25 years old from South Limburg participated in an online survey (38\% loweducated, 62\% high-educated). Participants were recruited through their school or through a sample from the population register. The study sample was weighted for population based characteristics such as age and sex. Topics included in the survey were experience with pregnancy, sexting and sexual diversity. Outcomes were compared between low-educated and high-educated participants using chi-square tests with complex samples.

Results The study showed that $6.4 \%$ of low-educated youngsters had experience with pregnancy compared to $0.9 \%$ of high-educated youngsters $(\mathrm{p}<0.001)$. Fifteen percent of those with a lower education level had a negative experience with sexting compared to $8 \%$ of the high-educated youngsters $(\mathrm{p}<0.001)$. Twenty-seven percent of the low-educated youngsters did not accept homosexuality compared to $15 \%$ of the high-educated youngsters $(\mathrm{p}<0.001)$. In addition, $21 \%$ of the low-educated youngsters and $11 \%$ of the high-educated youngsters did not accept gender non-conformity $(\mathrm{p}=0.001)$.

Conclusion Low-educated youngsters had more experience with pregnancy, more negative experiences with sexting and more often a negative attitude towards sexual diversity in comparison to high-educated youngsters. This indicates that low-educated youngsters are an important target group for sex education and sexual health prevention activities.

Disclosure No significant relationships.

\section{P405 SOCIAL LEARNING THEORY AND HEALTH BELIEF MODEL AS A PREDICTOR AND INFLUENCER OF YOUTH BEHAVIOR IN HIV TESTING}

Grace Gatimu*. Women Fighting HIVIAIDS in Kenya, Youth Outreach, Nairobi, Kenya

10.1136/sextrans-2019-sti.495

Background HIV counseling and testing (HCT) is widely considered an integral part of HIV prevention and treatment strategies in Kenya. However, recent studies show that slum youth are a highly vulnerable group due environmental factors namely, security, shelter, (economic) poverty, and risky behavior (social) and lack of amenities. Youth in urban slums of Kenya is a group at substantial risk for HIV infection, especially women. This paper examines the correlates of access to HIV testing, and checks if variation exists in these associations (context under testing and motivations for HIV testing (or lack thereof). Methods Drawing on 2013 data from Kenya National Aids Control Council, 6042 (51\% female) youth (12-22 years) living in Kariadudu and Korokocho slums in Nairobi, correlates of and motivations for HIV testing (or lack thereof) were explored using the Health Belief Model (HBM) as a theoretical framework. HBM, a social learning theory (recently relabelled social cognitive theory) is applied in this study to problems of explaining, predicting, and influencing behavior; on self-efficacy, and locus of control with respect to motivations for HIV testing (or lack thereof). Bivariate analyses were employed to assess reasons for or against testing.

Results $61 \%$ of males and $62 \%$ of females requested last HIV test while $41 \%$ of males and $51 \%$ of females reported mandatory HIV tests. About $75 \%$ females took HIV tests during pregnancy. Perceived risk for HIV infection was motivation to HIV testing. Over $50 \%$ of slum youth never tested for HIV because they believed they were not at risk.

Conclusion Voluntary HIV Testing Centres intervention helped the youth to accurately assess HIV infection risk levels and increase awareness, potential value of HIV testing, and motivation for testing. Mainstreaming Prevention of Mother-toChild Transmission services helped increase (mandatory) HIV testing rates among females. Routine testing and counseling among all visiting clinic clients can increase HIV status awareness among the youth.

Disclosure No significant relationships.

\section{P407 'MTV SHUGA': MASS MEDIA COMMUNICATION, HSV2 AND SEXUAL HEALTH IN ADOLESCENT GIRLS AND YOUNG WOMEN IN RURAL SOUTH AFRICA}

${ }^{1}$ Maryam Shahmanesh*, ${ }^{2}$ Nondumiso Mthiyane, ${ }^{2}$ Natsayi Chimbindi, ${ }^{2}$ Thembelihle Zuma, ${ }^{2}$ Jaco Dreyer, ${ }^{3}$ Isolde Birdthistle, ${ }^{3}$ Sian Floyd, ${ }^{3}$ Nambusi Kyegombe, ${ }^{3}$ Chris Grundy, ${ }^{2}$ Siva Danaviah, ${ }^{2}$ Theresa Smit, ${ }^{4}$ Cherie Cawood, ${ }^{2}$ Deenan Pillay, ${ }^{5}$ Kathy Baisley, ${ }^{1}$ Guy Harling, ${ }^{5}$ Janet Seeley. 'University College London, Institute for Global Health, London, UK; ${ }^{2}$ Africa Health Research Institute (AHRI), Research, Mtubatuba, South Africa; ${ }^{3}$ LSHTM, London, UK; ${ }^{4}$ Epicentre, Durban, South Africa; ${ }^{5}$ London School of Hygiene and Tropical Medicine, Research, London, UK

10.1136/sextrans-2019-sti.496

Background Adolescent girls and young women (AGYW) In South Africa are at high risk of HIV and early pregnancy. MTV-Shuga, a mass-media edu-drama, improved some sexual health outcomes in a randomised trial amongst young people in Nigeria. We used the national free-to-air TV screening of MTV-Shuga (the "Down South" series), concurrent with the roll-out of a large scale-up of combination HIV prevention for AGYW - to test the hypothesis that mass-media edu-drama can improve the sexual health of AGYW in a rural and resource-constrained area of KwaZulu-Natal.

Methods We followed a representative population-based prospective cohort of females aged 13-23 between May 2017 and September 2018. We measured the relationship between exposure to MTV-Shuga (i.e., reporting seeing $\geq 1$ of 24 episodes; able to recall any storyline) and: incident HSV-2; incident pregnancy; condom use at last sex; uptake of HIV-testing and contraception; and awareness of HIV Pre-Exposure Prophylaxis (PrEP).

Results $2183(85.5 \%)$ eligible participants were surveyed at baseline, of whom 1853 (86.5\%) completed follow-up. MTVShuga exposure was low - $152(8.2 \%)$ reported seeing $\geq 1$ episode and $73(3.9 \%)$ recalled any storyline - while teenage pregnancy and incident HSV-2 were high (6.4 and 11.3/100 person-years respectively). MTV-Shuga exposed AGYW were from wealthier households $(\mathrm{p}<0.001)$ and urban areas $(\mathrm{p}<0.001)$. After adjusting for confounders, MTV-Shuga watching was associated with significantly greater awareness of PrEP $(\mathrm{aOR}=3.3,95 \% \mathrm{CI}: 2.12,5.14)$ and less likelihood (nonsignificant) of acquiring HSV-2 or early ( $<19$ years-old) pregnancy $(\mathrm{aOR}=0.55,95 \% \mathrm{CI}: 0.24,1.29)$.

Conclusion AGYW exposure to the MTV-Shuga edu-drama was very low in a setting where AGYW remain at high risk for STI, HIV and early pregnancy. Nevertheless, there is a suggestion that those who were exposed to MTV-Shuga had 
better sexual health outcomes. There is a need for strategies to raise uptake of such edu-dramas, and to evaluate whether wider coverage leads to population impact.

Disclosure No significant relationships.

\section{P410 PROGRAM EVALUATION TO PROVIDE HIV AND STI INFORMATION IN JUNIOR HIGH SCHOOLS IN KPANDO, GHANA}

${ }^{1}$ Danielle Vos, ${ }^{1}$ Kafui Bavor, ${ }^{1}$ Edem Richard Adjordor*, 2 Laura Koster. ${ }^{1}$ HardtHaven Children's Home, Kpando, Ghana; ${ }^{2}$ UNiTED Projects, Kpando, Netherlands

\subsection{6/sextrans-2019-sti.497}

Background We are a group of young people, aged 15 to 23 in Junior and Senior High School who are living with HIV. We are starting the conversation in our community to educate youth about HIV and STI. We do this together with our sister organization UNiTED. UNiTED conducts regular health education about HIV and STI in 13 schools. As 'The STARS' we conduct activities on World AIDS Days (WAD) in 19 schools. To evaluate the impact of our activities a program evaluation took place in June 2018.

Methods The program evaluation was a survey to assess students' knowledge about health behaviors. This survey was conducted in 4 schools that did not have the UNiTED health lessons and 3 schools that did have UNiTED health lesson and were also part of the WAD activities. The tool used was a modified version of validated Knowledge Attitude Practices (KAP) survey.

Results 382 JHS students participated in this study, aged between 10 and 24 years old, with a mean age of 14.6 years old. 195 attended form 1 and 185 attended form 2. On safe sex, STIs and teenage pregnancy, the intervention group scored $1.5 \%$ higher in comparison with the control group. The intervention group scored $0.4 \%$ lower on the topic HIV/ AIDS than the control group. Both results were not significant.

Conclusion While the results from the process evaluation of STI education show that the 2017 activities did not have the desired effect of increasing knowledge about STIs in the students which took part in the WAD activities in 2017 we are using the findings of the study to better integrate UNiTED's in school education with the WAD to create synergies for learning which we hope will increase the effectiveness of the two activities. We will conduct another evaluation of knowledge secondary school student's in 2019.

Disclosure No significant relationships.

\section{P411 ACCEPTABILITY OF A PHONE APP-BASED MOTIVATIONAL INTERVIEWING INTERVENTION FOR YOUNG MEN'S SEXUAL HEALTH}

Alexis Guzman*, Sara Landers, Meredith Nechitilo, Marina Catallozzi, Melanie Gold, David Bell, Susan Rosenthal. Columbia University Irving Medical Center, Pediatrics, New York, USA

\subsection{6/sextrans-2019-sti.498}

Background Motivational interviewing (MI) is an effective communication style for facilitating behavior change. Pairing MI with a smartphone app has the potential to engage young men, a traditionally hard-to-reach population. We assessed young men's experiences in a pilot study examining the use of a smartphone app with phone-based MI coaching by trained community health coaches (one female, one male).

Methods Fourteen (of 26) predominantly black and Hispanic men, ages 16-19 years, who participated in the pilot study were interviewed about their experience. They participated in app activities and coaching that addressed sexual health or fitness (comparison group). Interviews were transcribed and coded using thematic analysis.

Results Participants found the app activities and coaching to be acceptable. In both arms, the young men were asked about sexual health and reported being comfortable discussing it in this format. In the sexual health arm, they reported gaining knowledge about contraceptive methods and sexually transmitted infections, which some shared with their sexual partners. Participants were comfortable with the coach's gender; a benefit of a female coach was her perspective on sexual health. Most preferred phone rather than in-person or video coaching sessions due to not having to travel, ease of rescheduling sessions, and increased privacy regarding sensitive subjects. The most common obstacle to participation was phone replacement; others included parental monitoring and restriction of phone privileges. Over time, the young men felt positively about their connection to the coach. They sometimes viewed the coach as having medical expertise beyond the scope of his/her training.

Conclusion Phone app-based MI with community health coaches has great potential for use with young men for a variety of health issues including sexual health; however, it has unique obstacles. Phone accessibility may restrict young men's ability to fully engage and perceptions of a coach's expertise should be regularly clarified.

Disclosure No significant relationships.

\section{P412 AN EXPLORATORY ANALYSIS OF ASSOCIATIONS BETWEEN PSYCHO-SOCIAL FACTORS AND SYSTEMIC INFLAMMATION AMONG SOUTH AFRICAN YOUTH}

\begin{abstract}
${ }^{1}$ Ashley Henry*, ${ }^{2}$ Daniel Muema, ${ }^{2}$ Ngomu Akilimali, ${ }^{3}$ Fatima Laher, ${ }^{4}$ Manjeetha Jaggernath, ${ }^{5}$ Stefanie Hornschuh, ${ }^{1}$ Patricia Smith, ${ }^{1}$ Laura Cotton, ${ }^{4}$ Mags Bekinska, ${ }^{6}$ Jenni Smit, ${ }^{3}$ Janan Dietrich, ${ }^{3}$ Glenda Gray, ${ }^{7}$ Mark Brockman, ${ }^{1}$ Angela Kaida, ${ }^{8}$ Thumbi Ndung'U. ' Simon Fraser University, Faculty of Health Sciences, Burnaby, Canada; ${ }^{2}$ Africa Health Research Institute, HIV Pathogenesis Programme, Durban, South Africa; ${ }^{3}$ Perinatal HIV Research Unit (PHRU), Faculty of Health Sciences, University of the Witwatersrand, Johannesburg, South Africa; ${ }^{4}$ University of the Witwatersrand, Maternal Adolescent and Child Health Research Unit, Durban, South Africa; ${ }^{5}$ University of the Witwatersrand, Faculty of Health Sciencesperinatal HIV Research Unit (PHRU), Johannesburg, South Africa; ${ }^{6}$ MatCH Research Unit $(M R U)$, Department of Gynecology and Obstetrics, Faculty of Health Sciences, University of

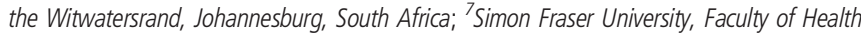
Sciences, Burnaby, Canada; ${ }^{8}$ University of the KwaZulu Natal, HIV Pathogenesis Programme and Africa Health Research Institute, Durban, South Africa
\end{abstract}

\subsection{6/sextrans-2019-sti.499}

Background Psycho-social factors affect biological processes, including inflammation and immune response, yet their contribution to gender and socio-economic disparity of HIV is not well understood. In South Africa, 38\% of new HIV infections occur in 15-24 year olds, with 3-times higher incidence among females. In this exploratory study, we examined associations between psycho-social factors and biomarkers of inflammation that may be linked to HIV acquisition in South African youth.

Methods Baseline plasma and linked cross-sectional survey data were obtained from the AYAZAZI study, which enrolled 425 HIV uninfected or HIV status-unknown youth (16-24 years 